\title{
GCU
}

Glasgow Caledonian

University

University for the Common Good

\section{Everyday dramas of conscience: navigating identity through creative neutralisations}

Ritch, Elaine L.; Brownlie, Douglas

Published in:

Journal of Marketing Management

DOI:

10.1080/0267257X.2016.1167108

Publication date:

2016

Document Version

Author accepted manuscript

Link to publication in ResearchOnline

Citation for published version (Harvard):

Ritch, EL \& Brownlie, D 2016, 'Everyday dramas of conscience: navigating identity through creative neutralisations', Journal of Marketing Management, vol. 32, no. 9-10, pp. 1012-1032.

https://doi.org/10.1080/0267257X.2016.1167108

\section{General rights}

Copyright and moral rights for the publications made accessible in the public portal are retained by the authors and/or other copyright owners and it is a condition of accessing publications that users recognise and abide by the legal requirements associated with these rights.

Take down policy

If you believe that this document breaches copyright please view our takedown policy at https://edshare.gcu.ac.uk/id/eprint/5179 for details of how to contact us. 


\title{
Everyday dramas of conscience: Navigating identity through creative neutralisations
}

\author{
Dr Elaine L Ritch, Glasgow Caledonian University \& Professor Douglas Brownlie, \\ University of Dundee
}

\section{Abstract}

The paper seeks to recuperate autonomy within debates around identity as the discursive construction of self (Foucault, 1984:42) through exploring the 'greening' of intensive mothering discourse and the emergence of new subject positions and practices of accountability. It argues that facets of ideologies of ethical and sustainable consumption are inscribed within this discourse, authorising identity work and furnishing everyday provisioning routines with significance and urgency; and that related social practices that are marked for 'greening' diligence or negligence are not merely situated and productive, but transformative of mothering identities, roles and norms. We report the findings of a study of a group of professional working mothers as they negotiate competing and conflictual spaces of doing 'green' mothering. This opens an analytical window on the diversity of signifying practices that characterise how informants play with boundaries and ambiguity in creative ways, using images of responsible consumption and sustainable living to negotiate appeals to social wellbeing while authorising claims to 'greening' competence. Our interviews capture discursive events that rearticulate social messages, mixing them with brand appeals and media content that situate the invention of 'new' mothering with regard to flows of 'greening' discourse. Inventive appeals and related subject positions speak of a repertoire of strategic messaging practices, themselves consistent with a heightened reflexivity shaping content and presentation through practices we understand as modes of neutralisation - forms of self-governance and accountability that seek to generate resources of resilience that help reinforce green mothering identity claims made to self and others. Through socialising 'sustainability' in this way we contribute to our understanding of the social surrogacy of brands (Sherry et al, 2009; Holt, 2012) and its problematics.

\section{Introduction}

"The green mother who successfully embodies the ideals of green motherhood does so not just by putting her child before her, but by sacrificing her own subjectivity and right to physical space in a capacity other than that of a mother" (Atkinson, 2014, p12)

As a site for rendering theoretical accounts of identity, social mobility and the discursive construction of self, mothering attracts much interest (cf The VOICE Group, 2010; Bailey, 1999; Afflerback et al., 2014): and for a paper inflected by consumer culture sensitivities, it is not controversial to suggest there are good reasons for this: not least among them being that "consumption, in its many varieties, is indispensable to the practice and experience of motherhood" (Cook, 2013:77). Indeed Cook writes that "[T]he place of mothers and motherhoods in commercial life represents one of the great undertold stories of consumer culture" (ibid, 2013: 75). In reviewing the territory he asserts the 
creative agency of mothering, resisting notions of motherhood as a circumscribed set of roles and norms conditioned into passivity by social exhortation and expectation. This is an important claim for CCT inspired research, not only because it opens up spaces of diversity between the intersectional discourses (Acker, 2012) of consumption, gender, class and intensive mothering; but also because it anchors itself around social actors and their immersive experiences of everyday lifeworlds put in play around those constituent discourses (de Certeau, 1984). We argue that mothering agency - its spaces of transference and ambiguity, creativity and resistance - manifests in the flux and flow of identity work done on the diverse cultural expectations surrounding the mothering role. As a result it is possible to see that mothering is a constructed institution of social cohesion which need not emerge spontaneously from any innate proclivity towards relational being always already shaped. Mothering identities can be seen to be works in progress, ongoing negotiations between society, economy and culture: and socially mediated practices of mothering are continually evolving as mothers re-evaluate their sense of self and otherwise reinvent themselves and the role as they see it (Atkinson, 2014) with the assistance of brands as transient vehicles of transference and transformation.

\section{Intersections}

In her recent study of the emerging discourse of 'green' mothering, Atkinson (2014) writes that "the presumed symbiotic relationship between mothers and the environment is facing renewed attention, this time in women's capacities as consumers, notably green consumers" (ibid, p 559). She continues: "[I]n contemporary mothering discourse, not only are mothers encouraged to consume, but they are also encouraged to consume in a way that combines concern for the child with concern for the environment" (ibid, p 559; Prothero, 2006). In this way the marketplace reconstitutes ritual, tradition and ceremony, recasting them through consumption as lifestyle practices of choice, individualism and identity. This advances the supposition of mothering solely as a provider who puts the child's needs first, to incorporating moral economy whereby commodities and practice are representative of political positioning that are idiosyncratic constructed. Given that many mothering practices are consumption based, especially provisioning for children (Brusdal and Frønes, 2013; Thomsen and Sørensen, 2006), it is no great surprise that mothering roles can present various lifestyle challenges (Hamilton and Catterall, 2010) where mundane provisioning practices are inconsistent with 'greening' (Carey, Shaw and Shui, 2008). And so it is that another source of anxiety and sanction enters the panoply of potential stressors surrounding the successful enactment of the gendered norms of the intensive mothering role: i.e. the threat of being found wanting, not only on matters of childcare, community and wellbeing, but on matters of environmental conservation and ecological justice, by yourself and by conforming others keen to judge and condemn. Behind individualised rationalisations and justifications for deviation from the idealised representations of practices of gender and mothering lurks this fear of being judged in the glare of ridicule, not only by other mothers, or by the powerful authorities of the medicalchildcare complex, but by themselves (Tonner, 2015; Thomson, 1996). 
Tonner (2015) describes the reliance of solutions from consumer culture that are used as an anchor by women to achieve belonging within mothering communities, as well as supporting the transitions that evolve within the mothering role; she also notes the complexity experienced within consumption as overwhelming due to an overabundance of choice and lack of supporting information. The social norm of invoking the edicts of intensive mothering as the basis for self-regulatory acts of diligence or negligence not only frames mothering practice, it reveals the power at stake among the intersecting constituent discourses of mothering identity. Add to expectations of altruism, communitas, self-sacrifice, coping, domesticity and moral superiority the anxiety of influence and power, and you have a sense of the heady mix of biopolitics (Foucault, 2008) working on mothering lifeworlds. Then add to that the emergent greening of mothering and you have a sense of the complex and conflicted nature of the evolving subject positions available to reflexive practitioners of contemporary mothering practice: that and the process of 'refraction' (Bailey, 1999) that women experience themselves undergoing as they pass from one eventful moment of transference and mothering transition to the inevitable next (Tonner, 2015).

\section{Mothering Bricolage}

This paper explores the constitutive force of consumption on the reflexive project of the 'green mothering' self, specifically in the context of working mothers and practices of clothing provisioning for children. It focuses on the lived experience of the roles that mothers insert themselves into and that they feel themselves inhabiting while working with everyday challenges of greening: for if with social disapproval comes self-blame and feelings of guilty non-conformity, why would mothers endanger themselves and their domestic relations through consciously violating the norms of green mothering doctrine; a doctrine that, in an ideal world, they would hold to, but that in practice they have to compromise, or otherwise negotiate away through constructing appeals, for instance, to the 'higher loyalty' of the tenets of intensive mothering? We argue that to better understand the impacts of the greening of mothering demands a return to context or social environment for a closer inspection of conditions and circumstances at work and the diversity of mothering identities that flow from juggling and bricolage skills acquired through social practices of bracketing, containment and negotiation. These practices are learned through the normative construction of gendered subjectivities within domestic relations of mothering (Smith, 2007; Smith, 1999); and brands can have a transient role to play here as cultural intermediaries, offering shelter and protection from the chill of selfblame through helping erect positions of affirmative mothering diligence and ecological safety.

Banister, Hogg, Budds and Dixon (2015) investigated the notion that brands validate legitimacy within the mothering role in relation to young women. They found that maternal identity was supported by brands as symbolic of their ability to be a good mother. In this instance, the brand was a cultural marker that offered assurance of care giving, provisioning and sacrifice; as the young mothers had yet to establish a career and many found themselves pregnant whilst in education, the brands they coveted were less affordable. Purchasing brands positioned as representative of good care were incorporated 
into the mothering performance to validate their worth as providers. As posited by Collett (2005), intensive mothering involves 'giving unselfishly one's time, money and love to one's children', something insinuated by so-called experts, marketing and celebrity life styles (p. 329). Within Collet's (2005) study, brands were also used as illustrative of good mothering, this time in relation to fashion; in order to manage this, her informants' utilised strategies to enable access to certain brands such as buying clothes in sales and ensuring the children were clean. This in turn developed their own identity: that of a good mother, a notion that Brusdal and Frønes (2013) suggest is played out within social setting.

This falls under the 'good/bad mother dichotomy', where the actions, values and brands signify adequate provisioning for the children that illustrates care and provides social differentiation, as well as amplifying love (Bannister et al., 2015; Hamilton and Catterall, 2010). We argue that this is also situated within a greening discourse, as predicted by Pereira Heath and Chatzidakis (2012) who considered the potential for conflict between 'good mothering' and the desire to practice sustainable behaviour (p. 664). For instance, in presenting themselves via the socially valorising credentials of the concerned green consumer, mothering actors will frequently have fallen back upon the utilitarian reckoner that affirms that the wellbeing of children must precede that of ecology. As sources of informational capital brands intervene in this calculus through offering a way of dealing with the lived experience of this cultural contradiction of green mothering; what Holt (2012) calls the 'salve'. The salve is the palliative balm of escape from the fixity of social positioning and inertia; it is a means of renegotiating circumstance and condition while generating conditions of beyond, of transcendence. Social mobility thus presents itself as the transformative potential of 'greening' sutured to mothering through a transcendental connectivity of affect and field. We employ the rhetorical device of 'distributed salvation' to render the discursive work of greening as a calculus of lived conscience wherein claim, judgement and appeal approximate the work of socialised environmental accounting: the gift of ecological forgiveness is situated with the brand and that of ecological sin with wayward consumers.

The logic of social differentiation suggests that from the local interplay of intersectional discourses of greening and mothering will emerge newly available spaces of social practice, recognisable as sites of resistance, empowerment, creativity, and, for some, deviancy. Much of the literature of the greening of motherhood (Cairns, Johnston, and MacKendrick, 2013; Atkinson, 2014) positions class setting as indicating belonging with a greening discourse, focusing on the purity of sustainable food that offers enhanced health attributes. It was also evident in the work by Bannister et al. (2015) where certain brands illustrated social status. This brings us directly to the concern of this study: practices of co-creativity at work within contemporary provisioning for children which challenge socially produced assumptions about greening and mothering. Given that the cultural logic of consumption is bound up with the urge to transcend the constraints of local givens, it is timely to study the scope available to mothers for negotiating practices of greening childcare within domestic routines. Transcending the fixities of coping and caring with the assistance of consumption allies and other forms of 'floating sociality' (Maffesoli, 1996) generates space for a diversity of situated mothering practices based on 
choice, inclination and the 'culture of quirk' (Hebdige and Potter, 2008). In this sense the greening of mothering becomes another arena in which resistive practices are played out. So whilst it is widely argued that consumption facilitates transitions to motherhood as social forms of ritual and custom previously did (Brusdal and Frønes, 2013; Hamilton and Catterall, 2010; Thomsen and Sørensen, 2006), we wonder how, if at all, it facilitates the transitions to 'green' mothering. Indeed the Voice group (2010) shares concerns that, although consumption can play a positive role during role transitions, "it can also, at other times, make transition a complicated, complex and confusing process" (ibid, 373).

To explore transitions towards green mothering our informants narrate their handling of clothing provisioning for their children in the structuring of everyday life events; and we consider the constitutive practices of mothering at work in the face of confusion and ambiguity toward greening amidst the consumerism. By our estimation processes of greening are the crucible, not only for identity work, transference and transformation, but for the multiple spaces of co-creativity whereupon mothering reveals itself to be contingent and provisional (Jägel et al., 2012). It is in this sense that acts of consumption summon existential anxieties of risk society (Beck, 1992) as they illuminate taken for granted household habits of domestic worlding; fashioning living spaces for provisioning and rearing. The days when mothering was unmarked for 'ecological diligence' have passed and we suspect there are tensions associated with various positions of expressed ecological concern (Szmigin et al., 2008) within the greening of consumerist mothering that invite interrogation .

\section{Illustrative Study}

To explore these issues we report the findings of a study of a group of young professional women, 28 working mothers (see table 1), as they negotiate the multiple competing and conflictual spaces surrounding practices of kids' clothing provisioning as they implicate positions of sustainability. The informants were selected as previous literature had identified motherhood as inspiring concern for environmental issues (Ha and Stoel, 2004; Prothero and Fitchett, 2000), as had higher levels of education (Ma and Lee, 2012; do Paço and Raposo, 2010). Therefore, it was assumed that mothers who worked in a professional occupation (requiring a degree for employment) would have greater knowledge of the concerns surrounding the impact of consumption on the environment, which in turn would inform their practice. Additionally, organic food was preferred by mothers due to assumptions of added health attributes (Gam, Cao and Kang, 2010; Carey et al., 2008), and it was questioned whether this transferred to preferences for organic textiles. We maintain an empirical focus on the negotiated spaces of identity hosted by those practices, revealing their generative character through interviews and label cues. We also consider the importance of everyday acts of co-creativity consistent with those practices. We suggest that analysis at the level of mothering discourse illuminates the nuance of everyday creativity and juggling practices at work within the management of kids' clothing provisioning. 
Table 1: Demographic profile

\begin{tabular}{|c|c|c|c|}
\hline $\begin{array}{l}\text { Participant } \\
\text { number } \\
\text { (age) }\end{array}$ & $\begin{array}{l}\text { Occupation (work commitment: full- } \\
\text { time/ part-time/ number demotes } \\
\text { number of days or hours worked per } \\
\text { week) }\end{array}$ & $\begin{array}{l}\text { Family structure (age of } \\
\text { children and gender (f) } \\
\text { female and (m) male) }\end{array}$ & Marital status \\
\hline $1(41)$ & Befriending service coordinator (32 hours) & 14 (f), $11(\mathrm{~m}), 8$ (f), 8 (f) & Married/cohabitating \\
\hline $2(28)$ & Probationary teacher (full-time) & $8(\mathrm{f})$ & Single \\
\hline $3(43)$ & Lecturer (full-time) & $8(\mathrm{f}), 5(\mathrm{~m})$ & Married/cohabitating \\
\hline $4(43)$ & Manager (full-time) & $10(\mathrm{~m}), 7(\mathrm{f})$ & Married/cohabitating \\
\hline $5(42)$ & Lecturer (part-time) & $8(\mathrm{~m}), 6$ (f) & Married/cohabitating \\
\hline $6(37)$ & $\begin{array}{l}\text { Financial services compliance officer (part- } \\
\text { time) }\end{array}$ & 12 (f), 9 (f) & Married/cohabitating \\
\hline $7(40)$ & Admin secretary (part-time) & $9(\mathrm{~m}), 6$ (f) & Married/cohabitating \\
\hline $8(47)$ & Company director (45 hours) & $9(\mathrm{f}), 6(\mathrm{~m})$ & Married/cohabitating \\
\hline $9(34)$ & Student guidance advisor (18 hours) & 3 (f), 1 (f) & Married/cohabitating \\
\hline $10(48)$ & Tourism (part-time) & 9 (f), 6 (f) & Married/cohabitating \\
\hline $11(39)$ & Primary teacher (17.5 hours) & 6 (f), 4 (f) & Married/cohabitating \\
\hline $12(39)$ & Solicitor (22.5 hours) & $8(\mathrm{~m}), 5(\mathrm{f})$ & Married/cohabitating \\
\hline $13(47)$ & Police operations coordinator (18 hours) & $10(\mathrm{f}), 7(\mathrm{~m})$ & Single \\
\hline $14(36)$ & $\begin{array}{l}\text { Secondary school teacher ( } 3 \text { days per } \\
\text { week) }\end{array}$ & 3 (f), 2 (m), 2 (f) & Married/cohabitating \\
\hline $15(38)$ & Book keeper/administrator (21 hours) & $6(\mathrm{~m}), 4(\mathrm{f})$ & Cohabitating \\
\hline $16(39)$ & Accounts assistant (28 hours) & $4(\mathrm{~m}), 2$ (f) & Married/cohabitating \\
\hline $17(28)$ & Retail (8 hours) & $8(\mathrm{f}), 4(\mathrm{~m})$ & Married/cohabitating \\
\hline $18(40)$ & Physiotherapy lecturer (19.5 hours) & 2 (f), pregnant & Married/cohabitating \\
\hline $19(42)$ & University administrator (18.5 hours) & $6(\mathrm{~m}), 5(\mathrm{~m})$ & Married/cohabitating \\
\hline $20(39)$ & Social researcher (16 hours) & 6 (f), 4 (f), 6 months (f) & Married/cohabitating \\
\hline $21(34)$ & Chartered accountant (28 hours) & $15(\mathrm{~m}), 12(\mathrm{f}), 4(\mathrm{~m}), 3(\mathrm{~m})$ & Married/cohabitating \\
\hline $22(48)$ & Solicitor/mediator (full-time) & $16(\mathrm{~m}), 14(\mathrm{f}), 11(\mathrm{~m})$ & Married/cohabitating \\
\hline $23(42)$ & Senior lecturer (full-time) & $2(\mathrm{f})$ & Married/cohabitating \\
\hline $24(36)$ & Research administrator (full-time) & $5(\mathrm{~m})$ & Single \\
\hline $25(40)$ & Lecturer (18 hours) & $9(\mathrm{~m}), 5(\mathrm{f})$ & Married/cohabitating \\
\hline $26(43)$ & Administrator (28 hours) & $4(\mathrm{~m})$ & Married/cohabitating \\
\hline $27(44)$ & Lecturer (21 hours) & $6(\mathrm{~m}), 3(\mathrm{f})$ & Married/cohabitating \\
\hline $28(42)$ & Solicitor (full-time) & $6(\mathrm{~m}), 3(\mathrm{~m}), 11$ months $(\mathrm{m})$ & Married/cohabitating \\
\hline
\end{tabular}

In an attempt to visualise our theorisation, figure 1 depicts the discursive fields of intersectionality as they generate subject positions among the frictional overlaps. The left side of the figure presents a general abstraction at the level of social roles, context and identity; the right side presents the specifics at work within particular permeable discursive sites as they interpenetrate, producing generative spaces of improvisation in the overlap. Practices of negotiation are understood through the notion of artful rhetorical appeals, reconstituted breaches of discourse. Those appeals are understood as moments of refraction, where identity positions reveal themselves by virtue of the internal dialogues vocalised by our informants through the medium of shared narratives of clothing provisioning. We distil those narratives into appeals which seek to capture the logic at work within them as 'neutralising strategies' (Skyes and Matza, 1957), steps taken by mothers to negotiate the rhetorical territory through actively shaping the claims made of themselves by themselves and significant others through practices of bracketing and conditioning. In their original study Sykes and Matza (1957) coin the term 'neutralising strategy' to refer to the various calculating rationalisations made by criminals to exculpate themselves, or otherwise assert some sort of transfigurative explanation for deviancy and criminality by way of rehabilitation, mitigation or restoration. In this study 
we find the idea of calculative rationalisations and rhetorical ploys of relational being helpful in understanding the affective force behind the calculus of lived conscience wherein claim, judgement and appeal approximate the work of socialised environmental accounting.

\section{Figure 1: Discursive intersectionality}

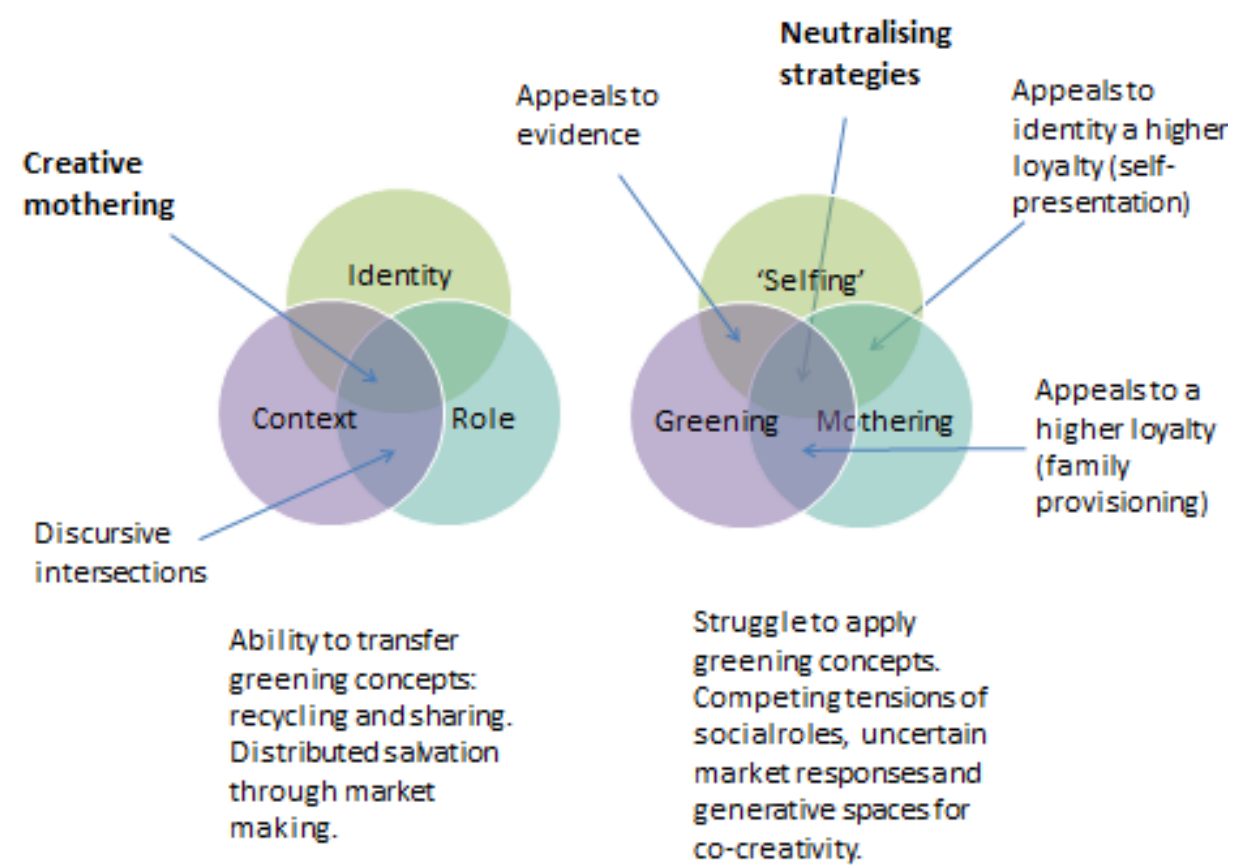

Figure 1 illustrates where the discursive intersections of creative mothering occur, through negotiating idealising facets of the lifeworld as experienced by the informants. On the left the spheres of idealisation capture energising context, role and identity as three defining fields: for this study, the energising context is 'greening' which bleeds into the idealising of the mothering role as well as tropes of available mothering identities. This figure represents the 'multiple women/mother identity' described by Tonner (2015, P. 12), deriving from the transition of the mothering experience; this encapsulates prepregnancy, birth and continues as the child grows and their needs and values change. The women/mother identity also evolves through maintaining a sense of self, which we refer to as identity to describe how the informants view their self-presentation. This approach is similar to May's (2015) description of the sociology of personal life that 'understands human life as comprised of complex, interconnected spheres, as selves connected to other people as well as culturally and socially embedded' (p. 364). Additionally, Bannister et al. (2015) found that their sample of young mothers rejected fashion worn by their peers, preferring to adopt clothing they felt was symbolic of motherhood. We argue that the role of mother is juxtaposed with other roles a woman undertakes, such as wife, professional, mother, and is also representative of social identity (Collett, 2005). This is a useful observation to frame the research as a dynamic journey in which identity and role is interjected with social change; such change, or the challenges within the mothering role, cannot be predicted due to the idiosyncratic nature of lifeworld experiences (May, 2015). 
Within this, creative mothering achieves the successful enactment of family provisioning that self-regulates practice as combining concern for the child and the environment. This manifests through harnessing the cultural appeals of brands that provide salvation, such as purchasing organic/Fairtrade food and recycling waste, practice which was informed and endorsed through societal networks. The spheres on the right represent breaches of the ideals of intensive green mothering, providing space for the felt need of appeals to appease breaching practices that contradict their desire to conform and contain personal risk. This emerged when discussing fashion consumption practice, where the industry is shown to be less proactive in addressing issues around greening concepts and consumer anxiety generated by breaches of social norms. In this sense, appeals offer salvation through positioning familial needs as subject to a higher loyalty, borne out circumstances to cope with the demands of motherhood. Narratives that illustrate those appeals are presented in Table 2 below and are followed by examining three appeals in further depth.

\section{Table 2: Narratives illustrating rhetorics of neutralisation}

\section{Description}

$\begin{array}{ll}\text { Appeal to a } & \text { Despite suspecting that } \\ \text { higher } & \text { inexpensive fashion derives } \\ \text { loyalty } & \text { from exploitative practice, } \\ \text { (family } & \text { providing clothing for the } \\ \text { provisioning) } & \text { children is prioritised }\end{array}$

\begin{tabular}{|c|c|}
\hline $\begin{array}{l}\text { Appeal to a } \\
\text { higher } \\
\text { loyalty (self- }\end{array}$ & $\begin{array}{l}\text { Sustainably produced fashion } \\
\text { not considered fashionable or } \\
\text { appropriate and not sought }\end{array}$ \\
\hline
\end{tabular}

Appeal to Deliberating what the best evidence
Deliberating what the best
outcome for workers in developing countries is, is any job better than no job? Also, recognising the monetary exchange in countries does not equate, therefore, not really knowing if the wages are exploitative

\section{Informant Example}

22

I feel uncomfortable with [the low price of supermarket school clothes]. I do it because [of] cost reasons

$4 \quad$ It is quite hard to get really fashionable organic and Fairtrade clothes, it tends to be ethnic [styles that] don't really follow fashion, they are their own fashion, in a way

$6 \quad$ You take factories away from certain parts of the country or the world, you could be taking away their only livelihood. For us, $£ 1.00$ a day isn't a huge amount, but $£ 1.00$ a day is there. But does that make it right? I don't know

\section{Appeal to a higher loyalty: family provisioning}

In response to the label cue that suggested children are exploited in Uzbekistan while picking cotton, I-24 sighed and shared:

It's something that I would condemn (doing nothing) but I don't feel that I know enough. I know if everybody does their bit, it will change things, but I don't see it as my personal responsibility particularly. I am trying my best recycling in terms of clothing, taking hand-me-downs. I will give my bit to charities, but, I can't change [what occurs in factories in other countries]. (I-24) 
The narrative of I-24 focuses on her lifeworld as a site of struggle as a single parent. The thought of taking responsibility for garment-workers was considered as overwhelming; to emphasise the appeal she states 'I'm just coping with me'. She claims to contribute to the sustainability agenda whenever she can, through charitable donations and recycling behaviours; but feels submerged in a life that makes it difficult to also take on global issues of exploitation as well as providing for her son. The demands made by the intense mothering roles were experienced as overwhelming. Despair was evident in the response from I-24 as she sought to dilute the guilt that her actions were in some way responsible for exploitative practice. Constraints operating within everyday domesticity are further outlined by I-8:

You can only work with what you have got, really. You can only fight so many battles in one day. You can't expect everybody to sort of be entirely green and ethical at a huge cost. (I-8)

In discussing the tensions of greening, I-8 refers to 'working with what you have got'. She alludes not only to working within the strictures of personal finances and a budget available for green clothing purchases: she also refers to the limited time she has available for green sourcing and shopping, and to the unreliable quality of information provided by manufacturers and retailers regarding the provenance of garments. She claims both manufacturers and retailers are poor in terms of providing information regarding the ecological imprint of the item and the working conditions under which it is manufactured. She attempts to explain the complexity of achieving some sort of ecological diligence where conditions and priorities conflict and growing children ensure that clothing needs regenerate themselves at frequent intervals; and priorities of needing to be able to pander occasionally to children's choices and contentment within the context of schooling and peer pressures. Regarding the issue of the exploitation of the children whose labour makes cheap and fashionable clothing available for our children over here, she appeals to the higher loyalty of the edicts of intensive mothering by asserting that her role is primarily for the wellbeing of her children. Salvation in this case is wrought from claims of normativity while at the same time appealing to impotence in the face of greater considerations. This feeling extended to all of the informants, with financial considerations underpinning the appeal to higher loyalty. However, in terms of food considerations there were some circumstances where family provisioning was supported by the green agenda, as indicated by I-24:

I buy fairtrade coffee, bananas. But as a mum, on a single income, food [is the] priority: to be able to buy my son healthy [food] within my budget. So, if organic [or] environmental [products] are part of that, then great. Buying things like, innocent smoothies, they are quite expensive but they are a good way of [getting] your five a day. Kids like them. I tend to buy the little bottles because if I open a big [bottle] it goes off in two days so [although] that's four containers, which isn't environmentally healthy, but to me the health benefits are more of a priority. $(I-24)$

In evaluating the virtues of the brand, the mothering role as provisioner is central and brand values that best address the functionality of this are selected. From this perspective 
domestic relations also condition the identity appeal, conforming to the green agenda when this aligns within practical provisioning. In this example, the utilitarian reckoner of the mothering dialogue supersedes ecological implications. Underpinning sustainable behaviours is the notion of providing her son with healthy food; she also explains her choice is not necessarily motivated by price, but sympathetic to the idiographic practice of her family lifeworld. As indicated in the quote, she wants to provide her son with the recommended intake of five portions of fruit and vegetables, advised within social campaigns for health. Health implications were expressed by a number of participants'; conflicted by the higher pricing incurred with natural food.

Yet, within this I-24 finds salvation through acknowledging that in some instances both the mothering values and the green agenda align; for example, she explains that the brand 'Innocent' positions products as addressing societal benefits, such as donations to charity included within the purchase price. This follows from the work by Bannister et al. (2015), Tonner (21015) and Collett (2005) where certain brands were symbolic cultural markers that validate the level of provisioning, not only illustrating the quality and additional health attributes, but including wider recognition of brands social credentials. However, this is followed by disengaging contradictory feelings which induce guilt; the trade-off was selecting individual portions rather than a larger single carton, increasing the packaging to be disposed of. The appeal is made through not wanting to be wasteful, disposing of food not consumed, particularly when the product is more expensive to purchase. Thus conflict is managed through appealing through the medical-childcare complex, whilst the green agenda addresses minimising food waste, another facet of sustainability. Her further efforts to align with the green agenda manifest through postconsumption disposal behaviours, including recycling packaging.

However, transferring a similar ethos to fashion consumption was more complex, particularly due to the inability to appeal the health considerations; but also due to the lack of fashion brands that acknowledged social and environmental concerns. Heightening the reluctance to source sustainably produced fashion was an assumption that fashion produced sustainably would be more expensive, a notion that was informed through observing that sustainably produced food was more expensive. The thought of paying more was inconceivable at a time when the demands upon the household budget were already compromised. The informants wages were reduced whilst on maternity or through reducing their working hours to spend time with the children. Coupled with meeting the children's growth needs and demands for commodities, negotiations and trade-offs were incorporated into their everyday practices. Sacrificing their own subjectivity and moral reasoning was temporarily bracketed through an appeal to make space to perform mothering duties. Therefore, the moral ideology they had constructed prior to becoming a mother was suspended, as provisioning superseded their value constructs. Examples included I-10 purchasing inexpensive chicken from the supermarket (which was not free-range) despite previously being vegetarian out of concern for animal welfare. Similarly, I-4 had practised voluntary simplicity (only purchasing what was required, see Shaw and Newholm, 2002 and Shaw and Moraes, 2009) before having her children and the small black and white television was replaced by a larger colour one at the request of her children. As postulated by other informants and reported in the study by 
Hamilton and Cattrall (2012), it was hoped that this was a temporary suspension, and that as the children matured their needs would be more flexible and less demanding. Some of the informants also hoped that their children would develop a similar sense of moral ideology and would apply this to their consumption decisions. However, to cope with their current lifeworlds, appeals were constructed to manage the challenge of familial provisioning, as illustrated through the quote from I-22 in Table Two above.

Other informants also described discomfort with the implications of inexpensive fashion, experiencing conflict through competing ideological agendas of clothing provision for their children and not wishing to contribute to exploitative practice. As I-13 explains: 'it's needs must. If you are buying clothes for children and you have got to watch your money, then price is very important'. I-13 judges her mothering role as furnishing everyday provisions, seeking social and personal sanctions that illustrate mothering competency. For example, she mentioned later in the interview that she experienced 'cringing' when noticing her son had outgrown his school trousers. She makes the assumption that this illustrates a lack of care to ensure her son had clothes that fit him, propelling this act as symbolic of her worth as a mother. Collett (2005) discusses children's appearance as representative of good care by the mother; clothing was used as a 'prop' that displays this to others within a social setting. Failure to do so contradicts the enactment of intensive mothering that centres on meeting the child's needs (Aitkenson, 2012). It was not only the social stigma of not being able to provide what the child needed that was at stake, the mothering instinct to fulfill basic nurturing needs, such as providing warm clothing also preceded the green agenda, as appealed by I-27:

I do have reservations about some of the clothing that I buy. For example, I know that the Tu range at Sainsbury's, cannot be as cheap as it is, without reason for it being that cheap. I avoid buying from there except very, very occasionally. They do extremely good winceyette, warm pyjamas, for kids and we live in a very cold house and their pyjamas are priced at $£ 10.00$ a pair as opposed to $£ 25.00$, which just for me is not a justifiable spend, for a six year old. (I-27)

I-27 is making a number of mothering appeals within her narrative; the behaviour is infrequent, borne out of necessity through protecting her child from the cold. Winceyette pyjamas are selected from utilitarian properties of warmth and despite allegations that inexpensive fashion is facilitated by exploitation, the supermarket provides a gateway of access allowing the successful enactment of nurturing and provisioning. Defence is also positioned at her son's age and the limited use of the pyjamas due to growth, suggesting a temporality of the behaviour. Perhaps once his growth slows down, she will feel able to justify paying a higher price for his garments. The mothering role authorises the choice, focusing centrality upon her child as a higher loyalty. It was not only finances and the children's provisioning needs that focused the appeal to a higher loyalty, assumptions surrounding the appearance of sustainably produced fashion also shaped behaviours.

\section{Appeal to a higher loyalty: self-presentation}

Along with notions that sustainably produced fashion was more expensive, it was not considered as following mainstream trends. As I-4 states, it follows alternative styling 
which is a statement within itself. Therefore, the appeal to higher loyalty included selfpresentation (Goffman, 1990). The fashion literature (Solomon and Rabolt, 2009; Workman and Studak, 2006; O'Cass, 2004; Gutman and Mills, 1982; Tigert et al., 1976) acknowledges that fashion is selected as expressive of self and identity, and this appeal transferred potential guilty feelings that consumption behaviours may contribute to exploitative practice within fashion production, as implicated within NGO campaigns. This included statements such as 'not to my fashion taste' (I-14) or 'I couldn't wear that to work' $^{\prime}$ (I-26). I-17 expresses frustration that the fashion industry has yet to acknowledge concepts of greening, whilst green fashion is designed to appeal to mainly on provenance as opposed to style:

It would be so great to walk into a shop that was reasonably priced where you thought every item in here has been made in a factory that has been inspected. And where all the workers have been paid a proper wage and that they have not been exploited. And I actually want to buy the things in that shop. Because there is that One World shop at the other end of Princes Street. I wouldn't buy those clothes. I don't relate to them at all [laughing]! (I-17)

I-17 explains that 'it would be so great' to be able to buy fashion that is both aesthetically pleasing and has been produced with respect for workers and the environment. In a sense, this would be one less burden of guilt in an already compromised world of biopolitics. Fashion brands and retailers could propel their authority to provide salvation and support mothering ideology alone with practical provisioning. I-17 also indicates that she has made the effort to source green fashion, yet was deterred by the styles available which may have represented her moral stance, but not her representational identity. Again, this links with Collett's (2005) study of putting on a performance, albeit for the mothers' appearance. Bannister et al. (2015) note the importance of women presenting externally their ability to cope with the demands of motherhood, as portrayed by the 'yummy mummy" cultural phenomenon that motherhood does not come at the cost of self-neglect. The notion of 'maintaining' (I-14) their sense of self and not looking like their liveworld consisted solely of domesticity was infused within the informants narratives; sacrificing their self-presentation in an existence that is already compromised through prioritising the children's health and well-being was dismissed as their appearance was indicative of their ability to cope with their challenging lifeworlds of employment and family life. I-27 takes a similar view:

The stuff in the Fairtrade shops, you get the odd gem, but most of the time you are looking at it and going, I wouldn't wear that. It's tie-dye, or it's a weird shape. And it is like you have suddenly got to look like somebody that is Fairtrade in order to buy ethically, which I find quite, insidious. I think you should be able to look completely ordinary, if you want to, but still have the option of buying [sustainably] and I think that's extremely difficult to do. (I-27)

I-27 explains that she has found the 'odd gem', an aesthetically pleasing garment that is sustainably produced, yet this is situated within a tirade of venting anger at the fashion industry which forces her to trade style against her moral ideology. The desire to enjoy playing with their appearance, which also contributed to feelings of well-being and 
confidence and represented self, continued to evolve during the transition of motherhood. Therefore, they wanted to hold onto 'a little bit of my pre-mummy identity' (I-14) and to make a further sacrifice through greening concepts was met with indignation. The importance of expressing self through fashion extended to the children, as felt by I-17 'some of their choices are so, limited, it's nice to let them express themselves that way', so they were given the autonomy to have involvement in their fashion selection. The socialisation processes was also acknowledged as something that enabled belonging and acceptable among their peers. In this sense, fashion supported the children's wellbeing and facilitating this was considered as integral to the mothering role. The intensive existential experience of nurturing children contained within the interplay of domestic relations was far more potent in informing mothering behaviours, especially when considering the joy it brought the children. The pleasure gained by the mother observing this joy is encapsulated in the quote below from I-10:

I do like to be on trend and I like my girls have all the stuff that they like. They gave me a huge big fashion show after going to Primark and we had such, such a good time. (I-10)

The 'fashion show' evidently inspired a sense of pleasure for I-10, who felt she had not only been able to provide her children with much needed garments to cope with the demands of their growth, but also the clothing that was considered by the children as fashionable and on-trend. This links with Hamilton and Cattrell (2010) who investigated how poverty restricts the consumption of what children request during socialisation to participate in peer belonging. They found that some of the parents sacrificed their own consumption to ensure that their children were not stigmatised by poverty. This notion underpins I-10 quote above, where her daughters' enjoyment was displayed through this shared experience, transcending provisioning to induce indulgent feelings that are not always experienced within the everyday strictures of the demands of motherhood. Consequently, new fashion played a role in not only illustrating the level of care in provisioning, but contributed to feelings of accomplishment that bolstered their children's self-esteem.

\section{Appeal to evidence}

The appeal to a higher loyalty was permeated by appeals to evidence. As indicated above in the discussion emerging from I-8, appeals were facilitated because the fashion industry does not provide information on production that allows empowerment to decide on the social or ecological impact. This left the informants deliberating the implications of production, for both garment-workers involved in production and the environment. Logic was revealed within a dialogue of cultural understanding, as I-21 illuminates:

Is any job, with any tiny amount of money better than no job at all? There are always going to be people working in such bad conditions, that it is clearly not right. I don't always know enough to be the one who judges whether it is right or wrong. (I-21) 
I-21 expressed uncertainty of workers in developing countries conditions citing how this fits culturally, including economical differences and expectations of salary. As such, she feels unequipped to condone allegations of exploitation or judge the morality of what occurs in factories overseas due to doubts about the quality of information and veracity of claims for better outcomes. This is similar to the response of I-14 when she states ' $I$ don' $t$ feel that I know enough'. This debate is continued with I-8, who also introduces the concept of Western imperialism:

What we regard as absolutely appalling conditions, some of them think as really quite good compared to other conditions. You can't just go in there with your Western ideas, there has got to be a process of them getting to that point. If we shut down a sweatshop, then that's 300 families without an income. [sharp intake of breath]. That's an ethical question in itself. (I-8)

I-8 is referring to imposing Western regulations onto developing countries, than developing countries evolving to embrace equitable legislation through their own development. She also refers to the cultural context, that what is deemed as unacceptable in the UK may be acceptable in developing countries. Further, she questions the morality of not providing workers in developing countries with employment, diminishing their opportunity to improve their economic prospects. This philosophy was expressed a number of times throughout the narratives, illustrating that predominantly, the informants did not want to contribute to inequality, but equally were unable to determine the extent of their poverty and servitude. The informants questioned the ethics of fashion retailers who have a presence on UK high streets, relying on NGO campaigns to guide the morality of consumption. This notion led to assumptions that primarily all fashion retailers were complicit to relying on exploitation of both garment-workers and the environment to make fashion that was affordable. To cope with feeling overwhelmed with the complex issues and without sufficient information in the marketplace to guide either the positive or negative consequences of fashion production, some informants disengaged with the issues. This response was particularly poignant whilst evaluating the EJF label where connotations of child labour were addressed, as illustrated by I-14:

Child labour is something I feel, strongly about. But at the moment there's quite a lot that I don't think properly, now that I have children of my own, because I can't actually bear to think about it. I have kind of shut down that bit of my brain, just because I can't engage with it emotionally. Whereas I have engaged with it emotionally in the past. I think that is affecting my behaviour probably. That [is] probably the reason that I can buy vests in Asda. Because somewhere down the line, even if it's not children, somebody's been exploited to get that cheapness, available to me. But it's still not an overriding factor over convenience, which is horrible. I get a glimpse of what might be happening, if it is something that is actually distressing then I switch off, like [I] don't actively switch off the radio, but kind of, my head does something. It's depressing me having this conversation, how much these things matter to me, in theory, and get still don't translate into the way I behave. (I-14)

A number of informants describe similar feelings of discomfort during the interview, almost as though during their everyday experiences they do not address the issues, but 
'switch off' (I-14), 'emotionally shut down' (I-17) or allow other factors to 'override' (I17) their morals. For example, I-6 stated that: 'Part of me wants to avoid looking at it' because she knew that she would have to address the issues of concern and potentially change her consumption behaviours. I-11 often found herself avoiding information she found upsetting:

I don't watch or listen to news or read the newspapers much because they are all negative. I feel guilty about that. I know I should be more up to date. I turned on the radio in the car yesterday and a baby had been abandoned. Everything's horrible. (I-11)

I-11 refers to 'everything's horrible' and 'negative', feelings that contrast with marketing to encourage consumption, particularly fashion marketing which focuses on the consumer-self, indulgence and frivolity. In particular, I-11 refers to a baby being abandoned and struggling to cope with the implication of rejecting a vulnerable child. This also positions the role of a mother as protector and caregiver to the fore, further strengthening the appeal to a higher loyalty. The literature positioned motherhood as a source of anxiety and I-11 expresses avoiding potentially distressing news which would further add to the complexity of provisioning. The drudgery of the everyday existential anxieties of risk society are escaped through moments of autonomy and creativity, carrying the burden of global market forces is rejected to cope with everyday demands of transitioning through motherhood, as experienced by I-10 through her daughters fashion show and positioned by I-24 at the beginning of the discussion. Nevertheless, the concept of poverty and servitude inspired discussions of how the food sector have enabled opportunities to support producers and workers, as indicated by I-3:

In terms of Fairtrade, it is a way of kind of saying well I've done my bit. Developing countries are in a mess because of what the West does to them. I think that one way to do it is to actually set fair market prices for the produce. If you were concerned about environmental issues or about global poverty and development issues then, my personal view would be that the way to do that is through, political action. Because I am not sure that individual behaviour actually makes that much of a difference. Because there are not enough of you doing it. (I-3)

I-3 observes that marketplace cues can encourage new patterns of both thought and deed. Similar to I-24, she claims to purchase Fairtrade products whenever she can as a way of deploying her purchasing power positively. She supports Trade Not Aid's strategy of empowering producers in developing countries to become self-sufficient and to provide them with a sustainable pathway out of poverty (Jones and Williams, 2012; Action Aid, 2007). In contrast to the wellbeing she experiences when purchasing Fairtrade food there is the frustration she feels at the lack of response of clothing retailers to issues experienced by involved green consumers: she claims there is no real choice in the highstreet for clothing sourced from sustainable production. With a number of other informants she feels impotent in the face of the huge global issues involved: that developed countries do exploit developing countries for inexpensive commodities, but that that is how global markets are structured and individual nations, never mind mothers, can do little to change that. As experienced by venting anger as a means to avoid guilt by her individual behaviour, she calls upon political movements to gather momentum and 
demand change. This is a similar approach of NGOs who also seek to pressure the fashion industry, through calling on consumer power to illustrate the depth of concern for exploitative practice. In contrast, the garment label that provided information of workers along with the efforts to reduce the ecological footprint of production evoked a positive response; it offered a green and ethically safe choice and sufficient information to support this, many claim they would opt for sustainably produced clothing where it was viable.

I like the name already [reading] women-made, eco-friendly, Fairtrade. Is that a wee girl sitting cross-legged? With something on her, or something [reading]. I absolutely love that. If the garment was nice, I just think that just adds absolute kudos, and is very cool, and, a good cause. I love the name, it explains a lot of stuff, but it is also, it's quite arty as well. They have obviously thought about their image. I like the name, Global Girlfriend, it's kind of snappy. It's marketing, without a doubt. But you can still be right-on and do marketing, because that tells you we are actually making money to do all these things. I really like that. I would be influenced by that. I would be drawn to buy that as a gift for somebody. Because you are actually, doing quite a lot. You are not only buying the garment, but you are actually buying into something else, an idea and a philosophy, in a Global Girlfriend kind of way. (I-10)

The Fairtrade movement offers I-10 the opportunity to address what she sees as unfair market structures; and she feels that ecologically sound purchases empower. This response was developed when commenting on the 'Global Girlfriend' brand, where labelling explains how its garments are made by a female cooperative in Nepal using organic cotton and vegetable dyes. Understanding the context of production and what consumption contributes to through familiar terminology was attractive to informants, as explained by I-10 above. The brand label engages this informant, although she states that style would still be a purchasing consideration, she relates to the implications of sympathetic production and wants to support the philosophy behind it: indeed, she lauds the brand's efforts to frame its garment production information as a marketing response to both the environmental and societal problems currently within fashion production and distribution. The labelling enables her to make an informed choice and contribute to the firm's ability 'to do all of these things' satisfaction emerging from individual consumption and the wider social movement of greening. I-10 also raised the ethos of 'Global Girlfriend' as a reason for gifting if the style was suitable. She suggests that the brand name, Global Girlfriend, speaks of transferring a gift from one girlfriend to another, with the added benefit of helping women in developing countries. This relates to the first quote in the discussion by I-24 of giving to charity and preferences for brands which have a social conscience; something that is also reminiscent of the 'giving' appeal of the TOMS footwear brand, that for every pair of TOMS shoes purchased the brand donates a pair to those in need. The garment offers a transferral of an ethic as an additional attribute, through making a positive contribution to a charitable cause, implying duality in not only giving a garment that would be appreciated, but through careful selection of a gift which aligns with the environmental and social issue preferences of the recipient. She considers that expensive branded sustainable goods may be more relevant for gift-giving. Indeed, I-9 and I-26 purchased gifts from UNICEF at Christmas time and expressed an understanding of the positive contribution that can be 
made through consumption and the importance to this of the linkage between manufacturers, brands and retailers. It was not only the connection made in the brand label between purchase and workers' quality of life that was socially valorising, but that the garment was produced without environmental degradation and the detrimental consequences of pesticides in raw material production. When evaluating the Global Girlfriend brand label, I-20 expressed her pleasure and surprise that high-street fashion can be produced without detrimental implications, by a social-enterprise established to support garment-workers by paying a living wage, using natural dyes and organic cotton.

I like the vegetable dye thing. I like [that] it's organic cotton. It tells you something about the producer and I think, oh, I am doing a good job because I am also supporting these people in a kind of fair way. It makes you feel good. (I20)

I-20 points out that the label 'makes [her] feel good' through explaining that it is produced without detrimental consequences for the environment and provides workers in developing countries with employment and dignity. 'I didn't know you could be so ethically aware with your clothes shopping' she observes noting that the label's information clearly evidences the brand's eco-credentials from avoiding toxic chemicals and pesticides.

\section{Concluding discussion}

The paper originated from the assumption that mothering identities, roles and norms were transforming to embrace concepts of greening within household practice. Although it may have been advantageous to include and discuss the ecological commitment of the women, they were selected as previous literature suggested that their demographic characteristics (for example, mothers with a higher level of education) would lean to preferences for sustainability, particularly with food (Ma and Lee, 2012; do Paço and Raposo, 2010; Gam et al., 2010; Carey et al., 2008; Ha and Stoel, 2004; Prothero and Fitchett, 2000). The informants' discussions routinely diverted to sustainable food and disposing of household waste preferences and behaviours, evidence of the food industry's efforts to educate consumers of the advantages of sustainable production (Centre for Sustainable Fashion, 2009), as well as social marketing campaigns that encourage recycling. However, the fashion industry at mainstream level has yet to address sustainability (exceptions include $H \& M$ and $M \& S$ ). The research sought to explore whether sustainable concepts that were considered important in one consumption context (food) transferred to another (fashion). The data captured the complexity of deliberating sustainable fashion within a myriad of competing moral ideology, logical reasoning and emotive responses to mothering and provisioning. The informants' narratives acknowledged their interest in sustainable concepts, with varying manifestations of behaviour; however, their knowledge and behaviour towards sustainable fashion was similarly ambiguous: they did not have sufficient information to determine what pertained to sustainable behaviour or what aspects of production led to unsustainability. As such, appeals were made to mitigate their behaviour, positioned around marketing themes of style, reward, image, price and quality. Additionally, their narratives characterised that the mothering role was not only focused 
on intensive insular provisioning, but expanded to include a broader perspective of global social and environmental issues; in this sense, assuming responsibility for nurturing was practiced at both an intimate familial level and through assuming responsibility for behaviours that impacted externally.

This study has unpacked facets of discourse around 'sustainability' which are widely inscribed within contemporary child-centred mothering identities. To understand mothers as creative practitioners of everyday living helps to understand how markets have parts to play in furnishing the routines of everyday provisioning; and in indicating ways in which new (sustainable) routines can emerge from destabilising habits of settled practices. We situate the work of habit in the interaction that occurs around identity at the level of the greening of mothering discourse and the various lifestyle challenges it presents, some of which are not consistent with environmental sustainability messages. From our empirical work, we derive a set of rhetorical appeals of distributed salvation that situate the gift of environmental forgiveness with the brand and ecological sin with the wayward consumer. Our results show that brands can position themselves as expert systems for delivering the socially valorising credentials of the green mother. We offer examples of how informants interact with brands to co-create responses to principles of green mothering: extracts illustrate the complexities, confusions and existential tensions experienced by mothers as they seek to negotiate the complex matrix of green mothering messages. We explore the work of rhetorical appeals that reveal the positioning work of participants as they seek the institutional authority and kudos of reference group proximity. Those appeals represent relational practices of identity work, including the negotiation of positioning with respect to debates around sustainability, indicating co-creativity framed by brand interpretive repertoires.

\section{References}

Acker, J., (2012) "Gendered organizations and intersectionality: problems and possibilities", Equality, Diversity and Inclusion: An International Journal, Vol. 31, 3, pp.214 - 224. doi: http://dx.doi.org/10.1108/02610151211209072

Action Aid, (2007) Who Pays? How British supermarkets are keeping women workers in poverty. Action Aid

(http://www.actionaid.org.uk/doc_lib/actionaid_who_pays_report.pdf)

Afflerback, S., A. Anthony, S Carter and L Grauerholz (2014)'Consumption Rituals in the Transition to Motherhood', Gender Issues, 31, 1, pp. 1-20. Doi:

http://dx.org/10.1007/8712147-01409115-0

Atkinson, L., (2014), Green moms: the social construction of a green mothering identity via environmentally advertising appeals, Consumption Markets \& Culture, 17, 6, pp. 553 - 572. doi: http://dx.doi.org/10.1080/10253866.2013.879817

Bailey, L., (1999) Refracted selves? A study of changes in self-identity in the transition to motherhood, Sociology, 33, 2, pp. 335 - 352. doi:

http://dx.doi.org//10.1177/S0038038599000206 
Banister, Hogg, Budds and Dixon (2015)

Beck, U., (1992), Risk Society: Towards a New Modernity. New Delhi: Sage.

Brusdal, R. and Frønes, I., (2013) The purchase of moral positions: an essay on the markets of concerned parenting, International Journal of Consumer Studies. 37, pp. 159164. doi: http://dx.doi.org//10.1111/j.1470-6431.2012.01094.x

Cairns, K., Johnston, J. and MacKendrick, N. (2013), Feeding the 'organic child': Mothering through ethical consumption, Journal of Consumer Culture, Vol. 13 No, 2, pp. 97-118. doi: http://dx.doi.org/10.1177/1469540513480162

Carey, L., Shaw, D. and Shui, E., (2008), The impact of ethical concerns on family consumer decision-making, International Journal of Consumer Studies, 32, 5, pp. 553 560. doi: http://dx.doi.org//10.1111/j.1470-6431.2008.00687.x

Centre For Sustainable Fashion, (2009), Tactics for Change, London College of Fashion (http://www.sustainable-fashion.com/wpcontent/uploads/2009/09/CSF\%20Volume $\% 203$ Tactics $\% 20$ for $\% 20$ Change.pdf)

Collett, J. L. (2005), What kind of mother am I? Impression management and the social construction of motherhood. Symbolic Interaction, 28, 3, pp. 327-347. DOI: http://dx.doi.org//10.1525/si.2005.28.3.327

Cook, D., (2013),'Introduction: Specifying mothers/motherhoods', Journal of Consumer Culture, 13, 2, pp. 75-78. doi: http://dx.doi.org//10.1177/1469540513482035

De Certeau, M., (1984) 'The Practice of Everyday Life', London: University of California Press.

do Paço, A.M.F. and Raposo, M.L.B., (2010) Green consumer market segmentation: empirical findings from Portugal. International Journal of Consumer Studies, 34, 4, pp. 429 - 436. doi: http://sx.doi.org//10.1111/j.1470-6431.2010.00869.x

Foucault, M., (2008) 'The Birth of Biopolitics', London, Palgrave Macmillan.

Gam, H.J., Cao, H., and Kang, M. (2010), Quest for the eco-market: a study of mothers' willingness to purchase organic cotton for their children. International Journal of Consumer Studies. 34, 6, pp. 648-656. DOI: http://sx.doi.org//10.1111/j.1470$\underline{6431.2010 .00898 . x}$

Goffman, E. (1990), The presentation of self in everyday life. Penguin books: London.

Gutman, J. and Mills, M.K. (1982), Fashion life style, self-concept, shopping orientation and store patronage: An integrative analysis. Journal of Retailing. 58, 2, pp. 64 -86.

Ha, Y. and Stoel, L. (2004), Internet apparel shopping behaviours: the influence of general innovativeness, International Journal of Retail and Distribution Management, 32, 8, pp. 377 - 385. http://dx.doi.org/10.1108/09590550410546197 
Hamilton, K. and Catterall, M. (2010), Consuming love in poor families: Children's influence on consumption decisions. Journal of Marketing Management. 22, 9-10, pp. 1031 - 1052. http://dx.doi.org/10.1362/026725706778935655

Hebdige, D and Potter, A. (2008), A critical reframing of subcultural cool and consumption. European Advances in Consumer Research. 8, pp 527 - 528.

Holt, D.B. (2012), Constructing sustainable consumption: From ethical values to the cultural transformation of unsustainable markets, ANNALS, AAPSS, 644, pp 236-255.

Jägel, T., Keeling, K., Reppel, A. and Gruber, T. (2012), Individual values and motivational complexities in ethical clothing consumption: A means-end approach. Journal of Marketing Management, 28, 3-4, pp. 373-396.

http://dx.doi.org/10.1080/0267257X.2012.659280

http://dx.doi.org/10.1080/0267257X.2012.659280

Jones, A.R.W. and Williams, G. (2012), Perceptions of fair trade labelling and certification: three case studies. Journal of Fashion Marketing and Management, 16, 2, pp. 246-265.

Maffesoli, M. (1996), The time of the tribes: The decline of individualism in mass society, London: Sage Publications.

May, V. (2015). Self, belonging and social change, Sociology, 45, 3, pp. 363-378. doi: http://sx.doi.org//10.1177/0038038511399624

Ma, Y.J. and Lee, H.H. (2012), Understanding consumption behaviours for fair trade nonfood products: focusing on self-transcendence and openness to change values.

International Journal of Consumer Studies, 36, 6, pp. 622-634.

DOI: http://sx.doi.org//10.1111/j.1470-6431.2011.01037.x

O'Cass, A. (2004), Fashion clothing consumption: antecedents and consequences of fashion clothing involvement. European Journal of Marketing, 38, 7, pp. 869-882. DOI: http://sx.doi.org//10.1108/03090560410539294

Pereira Heath, M.T. and Chatzidakis, A. (2012), 'Blame it on marketing': consumers' views on unsustainable consumption. International Journal of Consumer Studies. 36, 6, pp. 656 - 667. DOI: http://sx.doi.org//10.1111/j.1470-6431.2011.01043.x

Prothero, A. (2006), The F Word: The use of fear in advertising to mothers. Advertising \& Society Review. 7, 4. http://musde.jhu.edu/journals

Prothero, A. and Fitchett, J.A. (2000), Greening capitalism: Opportunities for a green commodity. Journal of Macromarketing. 20, 1, pp. 46 - 55. doi:

http://sx.doi.org//10.1177/0276146700201005

Sherry, J., Borghini, S., McGrath M, Muniz A, Diamond N \& R. Kozinets (2009)'Allomother As image and essence', pp 137-149, in Explorations in Consumer Culture Theory, Sherry J and E Fischer (2009), eds., London, Routledge. 
Shaw, D. and Moraes, C. (2009) Voluntary simplicity: an exploration of market interactions. International Journal of Consumer Studies, 33, 2, Pp. 215 -223.

DOI: http://sx.doi.org//10.1111/j.1470-6431.2009.00760.x

Shaw, D. and Newholm, T. (2002) Voluntary simplicity and the ethics of consumption. Psychology and Marketing, 19, 2, pp. 167 - 185.

DOI: http://sx.doi.org//10.1002/mar.10008

Skyes, G.M. and Matza, D. (1957) Techniques of neutralisation: A theory of delinquency. American Sociological Review, 22, 6, pp. $664-670$.

http://www.socqrl.niu.edu/miller/courses/soci380/sykes\%26matza.pdf

Smith, J.A. (2007), Identity development during the transition to motherhood: An interpretative phenomenological analysis. Journal of Reproductive and Infant Psychology, 17, 3, pp. 281- 299. DOI: http://sx.doi.org//10.1080/02646839908404595

Smith, N.C. 1999. Ethics and the typology of consumer value. In: Holbrook, M.B. (Ed.) Consumer value: A framework for analysis and research. London: Routledge. pp. 147 158.

Solomon, M.R. and Rabolt, N.J. (2009), Consumer behaviour in fashion. $2^{\text {nd }}$ Edition. New Jersey: Pearson Prentice Hall.

Szmigin, I., Carrigan, M. and McEachern, M. (2008), Flexibility, dissonance and the conscious consumer. European Advances in Research. 8, pp. $379-380$.

http://www.acrwebsite.org/volumes/13900/eacr/vol8/E-08

The VOICE Group (2010)'Buying into Motherhood? Problematic consumption and ambivalence in transitional phases', Consumption Markets \& Culture, 13, 4, 373-3. DOI: http://sx.doi.org//10.1080/10253866.2010.502414

Thomsen, U.T. and Sørensen, E.B. (2006). The first four-wheeled status symbol: Pram consumption as a vehicle for the construction of motherhood identity. Journal of Marketing Management, 22, 9-10, pp. 907 - 927. DOI: http://sx.doi.org//10.1362/026725706778935619

Tigert, D.J., Ring, L.J. and King, C.W. (1976), Fashion involvement and buying behaviour. Advances in Consumer Research. 3, 1, pp. 46 - 52.

http://www.acrwebsite.org/search/view-conference-proceedings.aspx? Id=5822

Tonner, A. (2015), Liminal mothers' negotiation of conflicting service consumption. Journal of Marketing Management. 32, 1-2, pp. 100-120. DOI: http://sx.doi.org//10.1080/0267257X.2015.1089306

Workman, J.E. and Studak, C.M. (2006) Fashion consumers a fashion problem recognition style. International Journal of Consumer Studies. 30, 1, pp. 75 - 84. DOI: http://sx.doi.org//10.1111/j.1470-6431.2005.00451.x 